\title{
Lindvist in the Sesame Institute Archive: An autoethnographic study
}

\section{Phil Jones}

Phil Jones (2018) Lindkvist in the Sesame Institute Archive: an autoethnographic study, Dramatherapy,39:2, 84101, DOI: $10.1080 / 02630672.2018 .1482362$

Intuition gives outlook and insight; it revels in the garden of magical possibilities as if they were real. (Jung 1954, 492)

With Thanks to the Sesame Institute for permission to use their archive.

This article is based on a visit to the Sesame Institute Archive (http://www.Sesameinstitute.org). My approach is based in ethnography and, more specifically, autoethnography. Ethnographer Angrosino defines archived materials as records stored by organisations, researchers, service agencies and other groups (Angrosino, 2005). He argues that archival material, from an ethnographic perspective, can connect with concerns about culture and communication in order to 'learn about culture, and an important part of culture: how people communicate' $(2005,64)$. Autoethnography, working within a qualitative paradigm, emphasises the value of a researcher's accounts of self-reflection to explore their personal experience and responses and connecting this autobiographical account to wider cultural, social or discipline based meanings and understanding. Maréchal summarises autoethnography as a form of research 'that involves self-observation and reflexive 
investigation in the context of ethnographic fieldwork and writing ' $(2010,43)$. My research with the Sesame archive uses an autoethographical framework: attending to my own responses about the nature of the materials and what they communicate, as an act of research. My intention was to work with my intuitive and reflective responses to the archive as a way to deepen an encounter with Lindkvist, including her work within the Sesame Institute, as reflected within the filed materials. Adams, Ellis and Jones (2015) argue that effective autoethnographic research should: value the personal and experiential response of the researcher; effectively offer a narrative of the response and make a contribution to knowledge. Hence, the approach within this article is less interested in an archive in relation to analysing historical progress or the accuracy of its items in depicting a phenomenon, and more as a way of exploring the ways elements of the archived content relate to me as an individual, with an interest in making discoveries about the interaction between my own thoughts and responses and the material I discover. In this way, the article draws on Adams, Ellis and Jones's (2015) criteria in its intention to be successful in presenting an account of my self-observation, imaginings and reflexive investigation as a contribution to our knowledge of Billy (Marion) Lindkvist's work as found within parts of the Archive.

\section{First encounter with the Sesame Archive}

On November $11^{\text {th }} 2017$ I visited the Sesame Archive. Within the Archive cabinet there were drawers containing a variety of different kinds of material, glimpsed through the tips of the suspension files. My aim was to work by taking a random selection of five samples, based on Kepley's (1984) writing about sampling in archives: operating in an intuitive manner by simply choosing what came to hand. I decided upon five files as my sample, as I judged I could write about this number within an article. I treated each file as a footprint either left by Lindkvist, or responding to her, and to the people she worked alongside. In line with 
Maréchal (2010) and Adams, Ellis and Jones's (2015) concepts, I will engage with each file's content as a personal journey for myself: responding and creating dialogue with the items, looking at them in terms of what they contain in their worlds of language and images and my own response to them. My encounter emphasises a personal reading of the materials, with only the occasional reference outside them to assist me in my responding, thinking about and imagining them.

As I reach into the cabinet and remove material, I think about the items in different ways. I imagine the Archive evolving over the past half century, with a mixture of items arriving there, placed by different people involved in Sesame across different decades. I imagine that some of the items were placed and kept there with a sense of intention to curate, to hold and to document for history, anticipating a moment such as this. Others, I imagine may have been less intentional, involving the casual depositing of material, rather like papers or handouts I place in my filing cabinet at work, with hardly any conscious intention or awareness, after I've been to an event or finished a line of work. I'm interested in both and what the intentionally treasured and the more casual reveal. I reach into each of the three drawers and select whatever comes to hand. I find something that is a bright blue pamphlet; a folder with letters in; a large binder with what looks like photographs; a clipped set of photostatted papers and an A4 envelope stuffed with writing. The following presents extracts from each item followed by my response. The extracts were selected very quickly and based on a scan of the file and chosen with a sense of scale for including in an article. I tried to work intuitively, following my curiosity, rather than with any cognitive pre-decided criteria - as this seemed in tune with the autoethnographic emphasis on the personal. 


\section{First item from the Archive}

\section{Text Extract}

\section{‘Open Sesame!’ Pamphlet dated 1977}

Because it can be difficult for teachers, patients, nurses and others to visualize just how easy it is to use simple drama techniques and just how readily those they care for will take part, Sesame has demonstration groups, since "seeing is believing". The mime group is called "Kats", and it is a small company of five women and two men, who have trained under a professional director for six years. It has developed a technique of communication which is neither danced as ballet, nor disciplined as true mime, but imposes a naturalistic discipline of its own. Short scenes, both serious and amusing, are played to music to handicapped audiences who are encouraged to take part actively in some of the scenarios. This they do to whatever extent they are able, some naturally, more quickly than others. When staff see the involvement of the handicapped members of the audience, and are themselves involved, they have a natural incentive to seek training. They, themselves, can then involve those they look after and help them to create their own mime scenes or improvisation.

...They have about fifty scenarios in their repertoire, and naturally vary the contents of their programme according to the age and ability of their handicapped audience. When playing to the public they choose a cross-section of items to illustrate the scope of their work. On the night referred to at the beginning of this article, one of the scenarios was called "Coming to Life". The players are not yet born, or, for the audience of small children, they are "asleep". 
Lying on the floor, they can neither see, move, nor hear until the music starts and the director says "now, you can feel the life coming into your fingers, your hands and arms, toes, legs, "and so on, until gradually the players are sitting up (still with their eyes closed). The sun falls on their faces and eyes and they see for the first time. (Again, this is adapted for very small children). The scene goes on and comes to a dramatic conclusion. It is not surprising therefore, that the teacher of the deaf says "Not for my boys" thinking particularly of the script. "But" he added, "I'll try to bring some of the to another performance and see what happened". A couple of evenings later, about 12 small boys sat in the audience. Most were deaf, and some hard of hearing. With the minimum explanation from their teacher, they followed every scene and in those intended for audience participation, joined in with great gusto and accuracy. We took the plunge and played "Coming to Life" telling the children to watch carefully because hey could take part when we played it through the second time. We were not disappointed. Only the slighted touch was requited, to the fingers and toes and when the sun shone on the eyes. As a member of the group, with my own eyes closed, I could not see, but I could feel the ways the boys were participating, and I am told that no one watching could have imagined that these children had not the full use of their senses. To the audience they were a sheer delight.

\section{Response}

What strikes me at first here is the way the extract from the pamphlet starts with difficulty: from the initial sentence with its list of professionals from education and medical health, to the teacher of the deaf later in the piece and his first recorded response of 'Not for my boys'. I imagine the late seventies and I parallel meeting difficulty at the start, in the first sentence, and how it might echo difficulty often being the first aspect of encounters involving promoting 
drama and movement in schools or hospitals at that time. It makes me think about the rock face and boulder hiding a cave and the words 'Open Sesame!' in the tale from a 'Thousand and One Nights' (2010). In a way, the work within the extract is trying to create entry in contexts that were, perhaps, as resistant and hard to access as a rock face. The account in the pamphlet takes us into the array of different professionals and a shift from their difficulty in visualizing 'simple drama techniques' in this context to being given something that physically embodies the work in a room with them by Lindkvist and 'Kats'. My association to that act - of connecting a mind's eye picture and a physically realized experience - parallels the early work of pioneers such as Lindkvist in taking something from an imagined possibility or dream, to making it happen in the world. The central tenet is that embodiment and sharing an action in the here and now, making something, is powerful. The 'Open Sesame!' text also reveals that this is not a solitary venture and it shows her alongside others, drawing on the tradition of the touring performance group. It makes me think of the need both for connection and support in making something new happen, alongside the determination and will of individuals such as Lindkvist in forging innovative territory. Beneath the 'Open Sesame!' account we can see the role of individual vision, the need and desire to collaborate with others. The text, whilst being produced for an organization, Sesame, has the feel of individual authorship in its' use of 'I': 'As a member of the group, with my own eyes closed, I could not see' and 'I am told'. This is a very particular kind of 'I' and, perhaps, tells us something of the individual woman, that I take to be Lindkvist: this ' $\mathrm{I}$ ' is inviting others to share in the move from imagined to real: is asking them to share in her individual imagined possibilities. It's there too, for me in her description of taking 'the plunge' as if diving into something uncertain in sharing the work with the boys and asking them to join in. 
The role of the 'demonstration groups' linked to 'seeing is believing' to me reflects the reality that in those early days there was very little evidence or proof - so belief is also a term that reflects the stage of the field at that date. There's no mention of dance and movement therapy in the extract: we have a combination of definition by negatives (saying what 'Kats' is not) combined with an interesting frame on what is on offer. The work is situated in negatives set against modalities seen in terms of form and tradition positioned as 'disciplined' mime and ballet. Set against these cultural disciplines is an emphasis on the value of what is provided: it is a 'technique of communication', emphasising participation and emotions ('serious and amusing'). I'm also interested in the notion of the 'natural' emerging in the pamphlet. The term is used many times: 'naturalistic discipline', the 'natural' variation of the scenarios used, the response of the audience, where staff or client have a 'natural' capacity to become involved and then a 'natural' incentive to go further to train. It's present, I think, in the later example of the teacher offering 'minimal explanation' with the group of deaf and partially hearing boys engaging with the drama and joining in 'with gusto', as if there is no need for much preamble or intellectual rationale - the impetus to enter is there, once the right access is opened. Implicit within this seems to notion that something is being discovered and shared that is a natural part of drama, which has been lost or disguised, and which the Kats group are revealing, bringing out of theater and drama. The art forms' hidden potentials are tapped and revealed so that people are not bound by the artifice of separation of skilled and unskilled or lines that divide those who can that engage by playing in the drama and those who cannot within the divide of formal theater. Perhaps this is part of the Sesame and Kats 'natural discipline': something that reveals the natural or elemental aspects of theatre? Here, perhaps, I wonder if there are gestures ready for connections to Jung, myth and symbol and the conceptual dialogue with archetypal and numinous material (Pearson, Smail and Watts 2013; Hougham and Jones 2017)? The engagements are described in ways that show this kind of 
'natural discipline': 'simple drama techniques', whilst the people in the experience are not told what to expect. Lindkvist does not present the process in a way that indicates she knows the effect - as if it can be reproduced over and over. Though the text shows us that there are 'fifty well tried scenarios' - Lindkvist takes us into the moment where she has her eyes closed as a participant and she does not assume that the work is having any effect: she doesn't take it for granted. It's a spontaneous occurrence and the results are fresh to us as a reader and to her, as she feels the response and is told about it by witnesses. I'm taken into this moment in the way she talks about the boys: 'As a member of the group, with my own eyes closed, I could not see' so she has to be told about the effect by others rather than automatically assuming it has occurred: 'I am told that no one watching could have imagined that these children had not the full use of their senses'. The drama is presented as naturally enriching and empowering - with the boys' sense of release that can't wait - this 'gusto'. There is something of the wild dance of this for me - the liberation and revelation that runs through - from the theme of coming to life, of dark to light and from the anxiety of taking the plunge and the teacher's "Not for my boys!" to their pleasure and involvement - 'sheer delight'.

\section{Second item from the Archive: a bundle of letters in a clip}

\section{Extracts From Letters}

(Hand written comment on letter, unidentified author) This was for the DHSS* with whom we were in communication a propos research I had undertaken in RSA** among black psychiatric patients. I am still active in pursuing this work.

*Department of Health and Social Security, United Kingdom

${ }^{* *}$ I'm not sure what this is, maybe Mary can help, please? PJ 
This is just a brief note to comment your attention to the accompanying appeal from Mrs. Marian Lindkvist our Founder and Director. The investigation she proposed is basically sound and holds high hopes of value in dealing with minority-group psychiatric patients in this country. Sesame has all the facilities and skills to carry out the investigation - with the exception of financial resources...

(Undated) Dr William AR Thomson, MD, Chair, Sesame Council

(Handwritten comment on letter, unidentified author) The late Dr Thomson was the Daily Telegraph Medical Correspondent

Her work in the fields of both physical and mental disabilities has been outstanding and widely recognized. Because her approach is both new and individual it is difficult to summarize, but from very modest beginnings it has developed until it has gained, it would be fair to say, the respect and admiration of every serious specialist in both fields who has seen it progress.

(Undated) Stella Mary Newton

Lecturer

Her methods have proved to be of central importance in the treatment of a wide range of psychological and physical disturbances. They have been adapted to such varied problems as those presented by autism, chronic psychosis and sophisticated analytical psychotherapy. Mrs. Lindkvist's outstandingly creative mind, combined with a cool, critical judgement, is evidenced by her work in many fields as, for example, her research on healing dances in Africa. 
(Date 2.2.86) Robert Hobson Consultant psychotherapist, Central Manchester Health Authority, Psychiatry Services

For over two decades (I) have watched as Sesame has grown in sophisticated techniques that have been energetically endorsed by distinguished members of the medical profession, providers of health care, and foundations that have awarded financial help to the undertaking (19 1. 1985) Dr George Bryan, College of Arts and Sciences, Department of Theater, University of Vermont

Marian Lindvist has made three lecture visits to New Orleans in the last decade, her latest in December 1985, when she was hosted by a consortium of new Orleans institutions, among them Loyola University, Charity Hospital, Children's Hospital and Special services of the New Orleans Public Schools. She spoke to the audience of therapists, psychologists, and professors concerned with various specialisms of emotional and learning disabilities. She has also lectured at the University of New Orleans under the aegis of the School of Education and psychology. Her appearance at a special conference concerned with handicapped people held at the John F Kennedy centre of the Performing Arts in Washington, DC in the late seventies, has opened many doors for her in the United States.

(25.1. 1986) Dr George Bryan, College of Arts and Sciences, Department of Theater, University of Vermont

\section{Response}

I was fascinated by this batch of letters, mostly from over thirty years ago, gathered together in a clip. A handwritten note offers some context - saying: 'This was for the DHSS with whom 
we were in communication a propos research I had undertaken in RSA among black psychiatric patient'. In my mind these handwritten notes may be written by Lindkvist, but this is a guess and the intention of gathering the letters itself is interesting - but the body of the letters provide, for me, snapshots of their time and the work of Lindkvist fashioned by those around her. On one level this can be understood as part of the process of lobbying for finances - but I want to look at it in a way that acknowledges that, but sees the choice, the way of doing this within the different letters and the selection of supporters and nature of support, as revealing. The contrast between expertise and financial resourcing to support and develop the expertise is connected to the phrasing ' Sesame has all the facilities and skills to carry out the investigation - with the exception of financial resources'. For me, implicit within these letters is the presence of power. Other, more established disciplines are being called on to vouch for this work: the 'MD', lecturers from the elite Courtault Institute, consultant psychotherapy and Bryan's language of 'endorsed by distinguished members of the medical profession, providers of health care, and foundations'. However, as I read them they become more than artifacts of past lobbying.

They start to make meaning to me as a record of interdisciplinary interest - the ways in which the work Lindvist is undertaking is connecting and reaching out to other domains. Here we have testimonies from people listed as being a newspaper medical correspondent, theatre lecturers and consultant psychotherapists. In my mind these morph into the identities of the 'converted' people from the first item I selected - the educational and medical health practitioners of the extract's first sentence, now no longer having 'difficulties' visualising it but enthusiastically being brought into the cause by Lindkvist, Kats and Sesame. I searched for the identity of Stella Mary Newton and assume she is the person who was an actress and OBE (1901-2001), working alongside Noel Coward and John Gielgood, on costumes for T.S. 
Eliot's premier of Murder In The Cathedral, lecturing at the Courtauld Institute of Art with an interest in costume design, and is the author of Health Art and Reason (1974). Living to one hundred, her recipe for longevity 'was to "be a vegetarian and never own a car" ' (White 2001, 1). An obituary I found said that, 'What she demonstrated was that every adversarial change should be met with imagination and initiative' (White 2001, 1). I imagine these vivid people meeting with Billy during the founding and expansion of Sesame's work and wonder about the passionate conversations and urge to support the new. I picture in my mind's eye Stella Mary Newington as a kindred spirit in the adversarial world of people not necessarily welcoming this innovative way of working with 'imagination and initiative' (White, 2001, 1). I imagine these advocates lending their words to add volition to applications for funding, promoting the work and offering the value of the power of their voice and the authority of their discipline to the work of Sesame and Lindkvist

The tenor of the letters is also interesting in the ways it creates pictures of the work and the woman in the work: 'her approach is both new and individual', 'outstandingly creative mind, combined with a cool, critical judgment'. Journeys that are developing tracks across relatively uncharted interdisciplinary territories are recognized 'research on healing dances in Africa' in the same paragraph as -'the treatment of a wide range of psychological and physical disturbance' bringing a sense of the novel, innovative alongside personal attributes brought to this journey. Here, I imagine is the combination and contrasting of the creative and the rational in Lindkvist. The letters, to me, say much about Lindkvist who selects these different disciplines: reflecting the new space being created between psychotherapy, medicine, work with people with learning disabilities and theatre. This bundle I've sampled from the Archive illuminates her choices and dialogue with existing disciplines and shows a new space developing between them, both in the physical spaces mentioned and in the conceptual space 
of the language used by the letter writers as they reach out to support the work of Sesame and Lindkvist. The spaces are presented as being a new birth themselves, as 'new ...institutions', their titles reflecting innovative affiliations such as 'Education and Psychology', or the presence of Lindkvist alongside people with disabilities entering into the Centre of the Performing Arts. In the letters we see, also, her work in his lights: in 'many fields', of audiences being brought together in mutual interest and curiosity in this new space of an event in New Orleans, for example, connecting 'therapists, psychologists, and professors concerned with various specialisms'. In addition, the wide potentials for clients are found here in relation to the new possibilities open to 'varied problems as those presented' from 'autism' and 'emotional and learning disabilities' to 'chronic psychosis'. 
Third item from the Archive

\section{A portfolio of photographs}

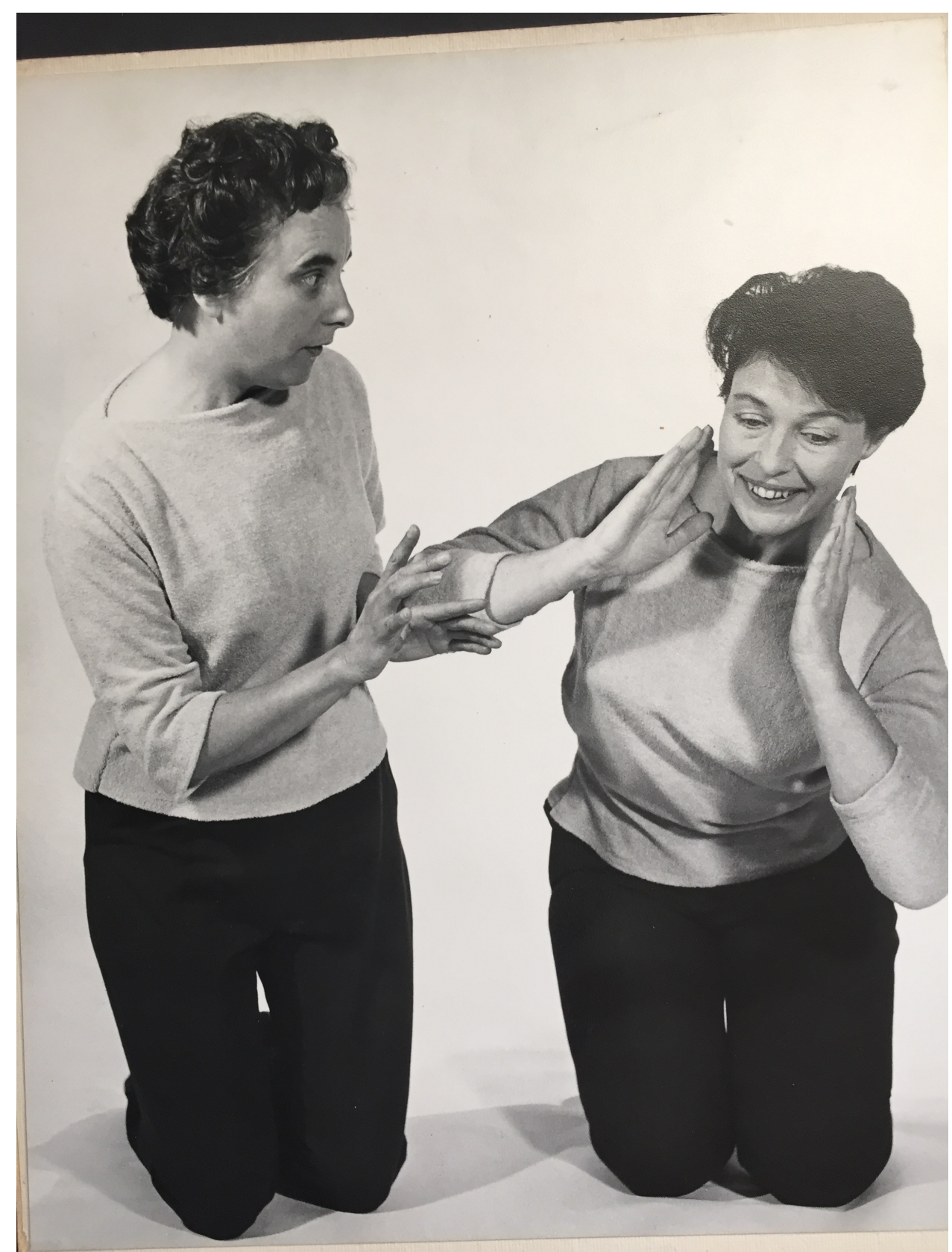


FIGURE A

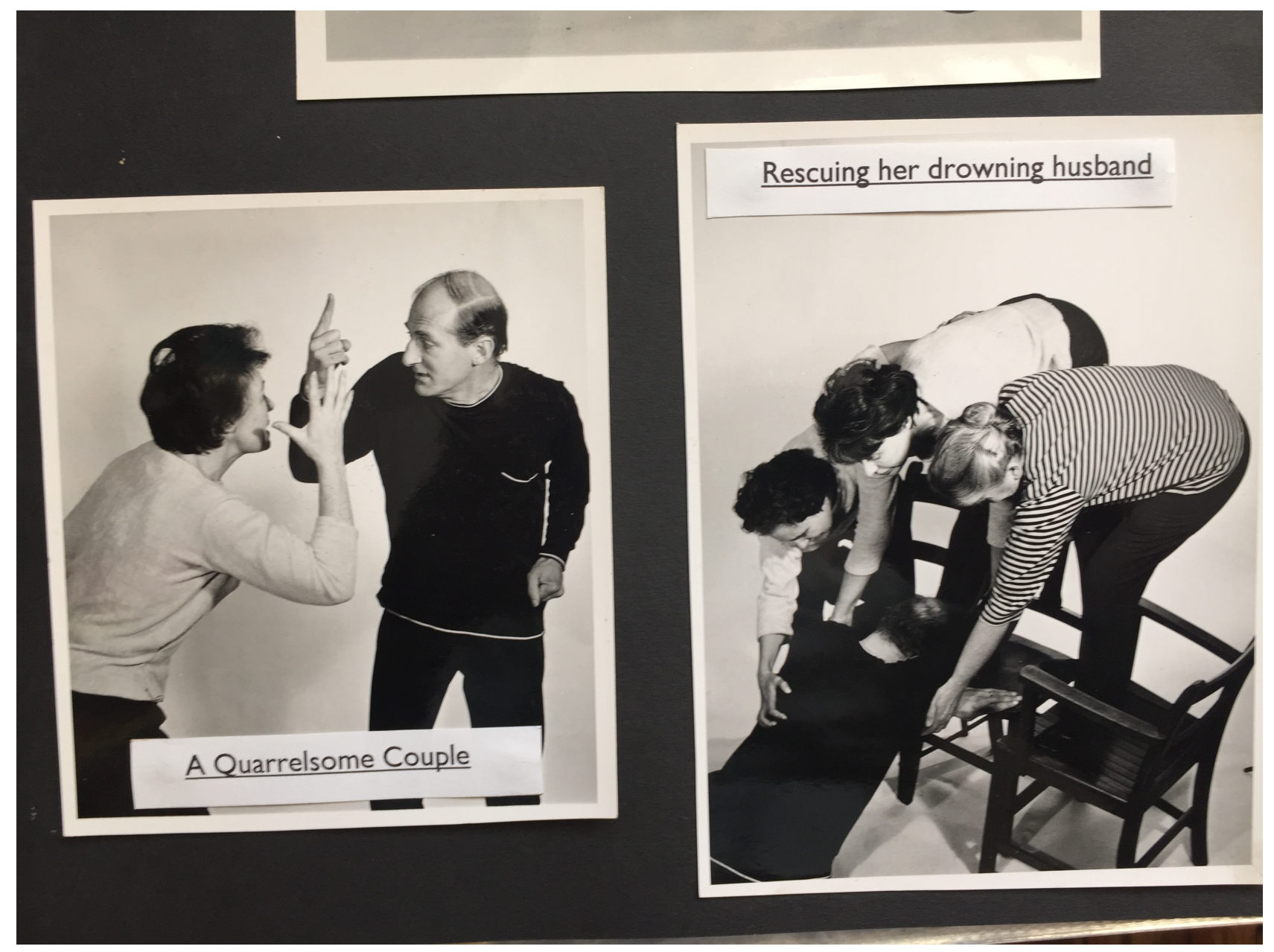

FIGURE B 


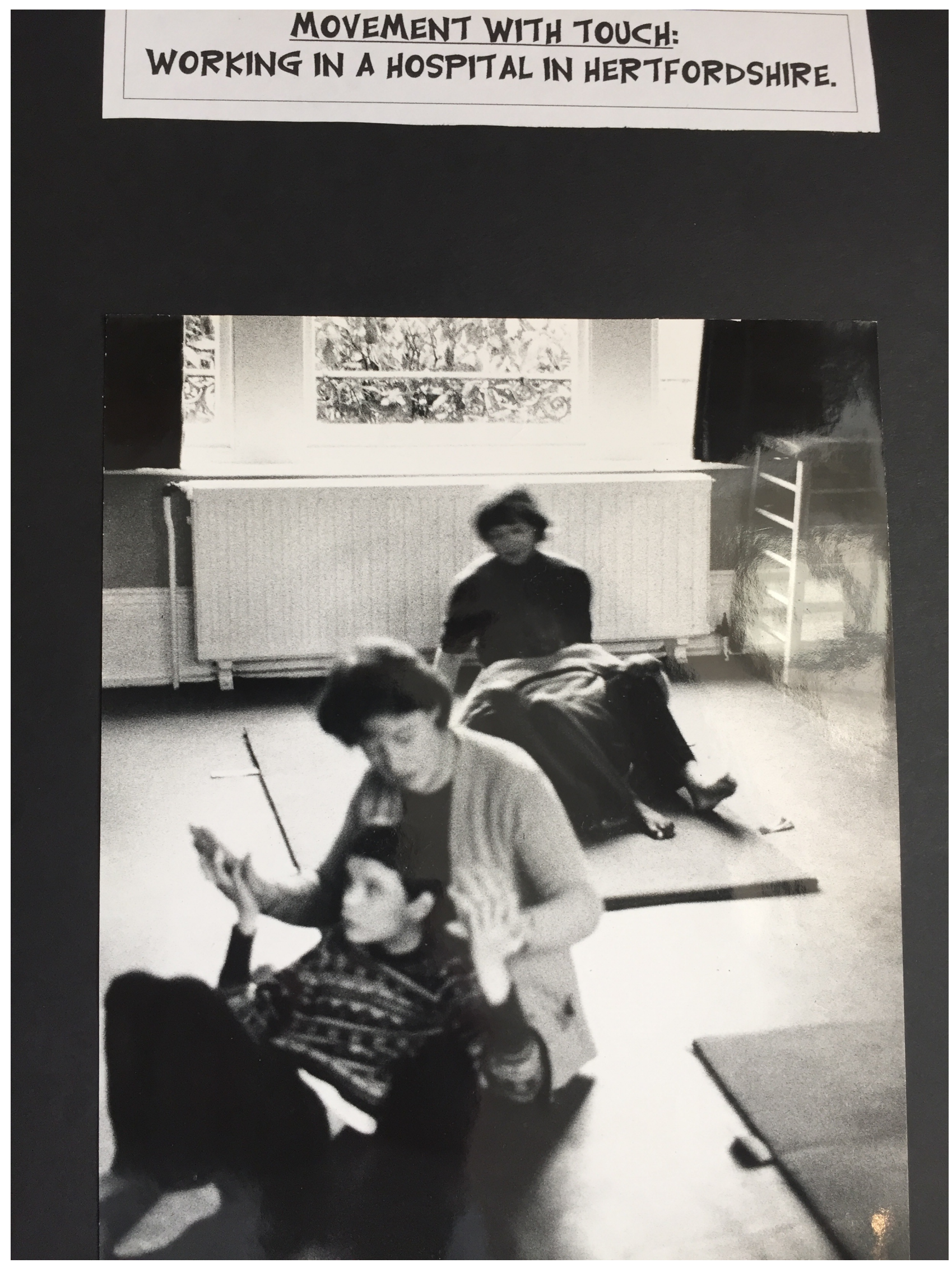

FIGURE C 


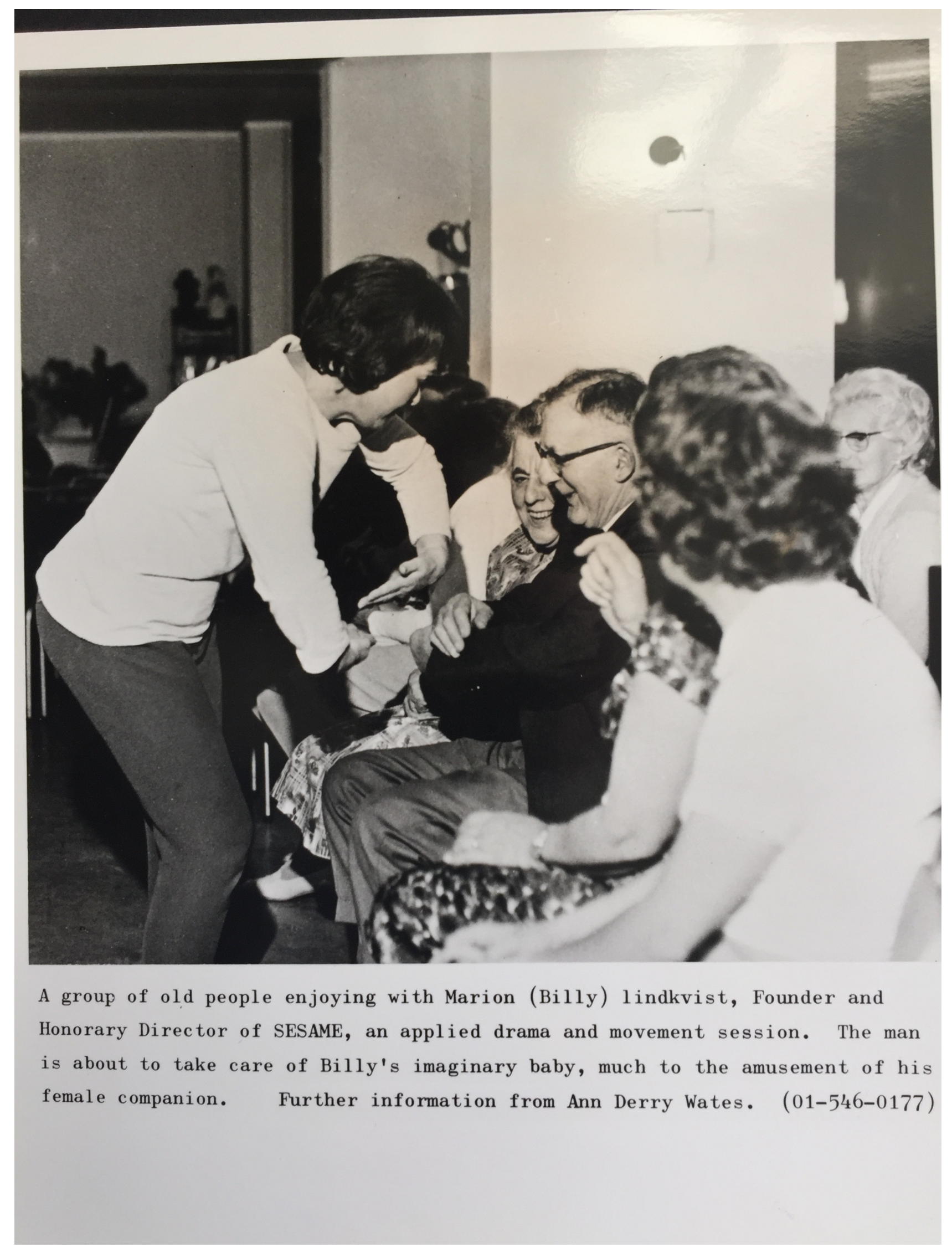

\section{FIGURE D}




\section{Response}

There were a number of black and white photographs collected in a large binder with titles such as 'Rescuing Her Drowning Husband' or 'Movement with Touch: Working in a Hospital in Hertfordshire'. They show a mixture of what is described as 'Kats rehearsals' and examples of practice. Out of the many I have selected four, two from each type. Figures A and B are from the rehearsals. Looking at them, I notice the way the individuals are dressed and their physical expressions- and it's interesting in that in my mind, after I've left the Archive building, I remember them as being dressed in black leotards, so traditional of mime from the era of the sixties and seventies, and when I look at them later I'm surprised and a little disappointed that they aren't and I've misremembered. I think it's because I associate them with similar photographs of the period and working with the body and face in ways that connote a specific tradition of theatre mime. To me the images seem to show more 'usual' theatre and mime forms: the group rehearsals seem firmly routed in these traditions. To me it is in the practice that the innovatory nature of the work emerges. The other two photographs (Figures C and D) show the group in action. They show different elements of practice and Lindkvist as part of the Kats team working with movement and drama in performance. One (Figure C) shows her working with a colleague with what is described as 'movement with touch'. I notice the way the child and she are moving in parallel, how physical contact between adult and child seems intimate, and imagine the quiet, small intensity of the relationship and work in the context of the large, Victorian, impersonal hospitals for people with disabilities of that era. I connect this back to the language of the first Archive item I found and its contrast between traditions of mime and ballet and a form of drama and movement that emphasises participation and access for those normally excluded from the arts. I imagine the moment where the child and Lindkvist together create access to these processes and the 
photograph takes on for me a moment of access - to this opening world of the profession in its early days. Another (Figure D), shows Lindkvist as performer in what is described as 'applied theater and movement'. Here we can see the shift from the rehearsal photographs to the 'session'. In it the audience or group are engaged with the drama, we can see all eyes are focused on the imaginary spaces Lindkvist is forming with her body and the man is reaching to take part in the holding of the 'imaginary baby' offered by Lindkvist. The audience is seated and divided from the performer in one way, but the faces of the group show engagement, and the text highlights 'amusement' and enjoyment. The focus is Lindkvist as the performer, but she moves into the group, so the experience becomes one of mutual joining and participation. I think of Lindkvist here as enabling and supporting the individuals in the audience to develop their creative capacity by joining, she offers an invitation. In my mind, the shape in her arms in Figure D isn't just a baby, I can't help but see it as an opening, a cave and think if it in terms of the 'Open Sesame!' from the first item - of the invitation to come into a new, revealed space of possibilities and potential.

\section{Fourth item from the Archive \\ Typed Manuscript In An Envelope}

\section{Text Extract}

Radius Sesame

Unnamed and undated

(Written in hand on first page) Audrey Wethered 
'Historical Review of Drama and Movement in Therapy'

Drama and movement as a form of therapy is still relatively new in the field of psychiatric research. Although a good deal of drama therapy has been practiced during the past years, with both mentally subnormal and mentally ill patients, few investigations into the methods used have yet been made.

One experimental study was carried out by Sesame in conjunction with the psychology department at Goodmayes Hospital, Ilford in 1970. This was aimed at investigating the effects of drama and movement therapy with long-stay schizophrenics. It was hypothesized that a treatment programme based on the principles of Child Drama, which aims at the explorations of the self and environment through physical action and fantasy enactment, would be of benefit to these parents. It was found that ye drama and movement group showed significant changes in imagination, co-ordination, interaction and communication, and physical involvement. They were also shown to exhibit an increased awareness of bodily self, greater acknowledgement of impulses and feelings stemming from a more primitive part of the personality, and a decrease in restlessness and aimless activity. Also indicated was an increased capacity for socially appropriate behaviour and a greater tendency to mix others and seek social contacts. In spite of the lack of emphasis on verbal discussion, changes were found on both verbal and non-verbal intellectual tasks.

Another experimental study was carried out by Sesame and the Psychology department at Leavesden Hospital, Herts in 1972. This was aimed at investigating the effects of group drama with long-stay subnormal disturbed adults. The film of this study indicated that the drama and movement group showed greater desire for social communication and an increase in co- 
operative behaviour throughout the course of the drama sessions. Statistically, however, these changes were found not to be significant although the film indicated that these changes did, in fact, appear to exist.

\section{Response}

The document is a typed manuscript, headed with the term 'Radius Sesame', which was the Religious Drama Society. Here, from nearly half a century ago, we have testimony to the drive and innovation of the collaborative work created by people working together. To me this find is a marker of contribution to work of a group of people for whom 'Sesame' became a language of collaboration and mutual discovery and that illuminates the collaboration of which Lindkvist was a part. There were two sets of material side by side one was an unnamed and undated typescript with the name Audrey Wethered handwritten on it (author of Drama and Movement in Therapy, 1973). Again, a theme in this Archive item is the combination of territory not travelled before, alongside interdisciplinarity and collaboration, as Sesame works with psychologists in a local hospital. The script is undated, but is shares much with Wethered's book 'Drama and Movement in therapy' from 1973 and there are no dates after 1974 cited - so it seems to locate it in this period. In reading it, my thoughts are that the language takes us into its period in what feels like a search for terminology. We have 'drama and movement as a form of therapy' and 'drama therapy' in the same sentence, with 'drama and movement therapy ' and 'a treatment programme based on the principles of Child Drama' following shortly after this, but with no differentiation of the relationship - whether saying there are parallels or differences between the phrases. I take this as reflecting a period where the terms and practices they represent sit side by side and the lively movement between them reflects a period of the exploration of relationships between different languages and concepts 
- but where they are used in an interchangeable way. One of the investigations the extract refers concerns a set of existing 'methods' and 'experimental study'. As I've written elsewhere, dramatherapy has yet to move into domains that the others arts therapies have moved into, such as the Random Control Trial or creating adequate amounts of research published in peer reviewed journals that can create Cochrane reviews. This marks an innovative turn in drama and movement in therapy, or drama therapy, involving something the field still struggles with: the urge and determination to create robust research. This item form the Archive, then for me is a marker both of collaboration and yet another angle of the startling innovative energy and momentum of Lindkvist.

Fifth item from the Archive

\section{A Photostatted Paper}

\section{Text Extract}

A Paper presented to the National Spring Conference on Mental Retardation at Exeter University $11^{\text {th }}-13^{\text {th }}$ April 1975 , by Marian R Lindkvist, Honorary Director of Sesame

'Some of you may have seen our film...severely disturbed and mentally handicapped young men at Leavesden Hospital, Hertfordshire. This illustrated the value of both the Laban art of movement principles and Slade's Child Drama in creating a marked change in the clients during sessions. Today you re going o see a film about our work with autistic and psychotic children at Smith Hospital, Henley on Thomas, over a period of six months. 
'The essence of the philosophy underlying Sesame's approach, that is the importance of the individual. The behaviour and individuality of these children epitomizes the differences in each and every one of us. It is, of course, a distorted and exaggerated picture. Nevertheless, it tells us something about ourselves as individuals within a group. These children were just "being themselves" because, being autistic, they would presumably have no reason to be anything else. We, on the other hand, have demand made upon us by society to which we adhere so that many of our differences are hidden, quote rightly so.

When people become truly involved in drama and movement (and naturally I am not speaking of theatre in this context), they reveal aspects of themselves which would, under normal circumstances, remain unobserved. It is observing these aspects that we can sometimes be of use to the sick and handicapped by feeding those with different skills, those in the medical profession and others, with information which may add to their knowledge of their client. We can, if we know our place in a treatment team, be an adult in the caring for the client. It is for this reason that Sesame offers training in applied drama to those in the caring professions, i.e. nurses, occupational therapists, teachers, social workers, and so on. They can incorporate our skills with theirs.

...Drama badly handled by a leader, or what is worse, not handled at all, in a misguided endeavour to produce hasty catharsis can cause the very same danger of throwing someone off balance so that participants may not be able to be contained and, what is more dangerous, may not be able to contain themselves. Sesame, therefore stresses the need for adequate training for those wishing to use dramatic techniques in the field' 


\section{Response}

This Archive item is a different testimony to the innovative work in research in drama and movement in therapy. For me, there is a struggle with the words used, from our contemporary situation - where language such as 'sick', 'handicapped' or our concepts of wellbeing and difference differ from those of the era of the extract. I see this as part of the complex negotiations with paradigms of healthcare and cultural and societal constructions of individuals. In this particular example, this concerns children, disability and approaches that filter the response of the professional to the individual through diagnostic or societal terms loaded with disregard for the individual and drenched with a foregrounding of pathology and difference as a deficit. Part of my personal reading of a document from a previous era needs to acknowledge such differences but, as I reflect on this, I think I also see in the paper itself tension with such generic labeling. On the one hand, there are terms that, at the time and subsequently, such as 'sick' or 'handicapped' have been rightly critiqued as problematic, in the ways I have mentioned. However, deeply present within this document I find a strong counter to contact with such ideas and linked practices. Here is a 'philosophy' and set of practices that offer a different momentum and a radically changed position: succinctly formed like a condensed 'essence' should be: the Sesame 'approach' and 'the importance of the individual' is placed directly at the heart of the deep belief fuelling the work. It's interesting to me that Lindkvist situates this clearly before the showing of the filmed practice: it provides a frame through which the audience can understand what they witness. The film provides a way of seeing the work through its recorded account, but the frame offered before this seeing provides another way of looking, conceptual, designed to assist eyes that might not be used to seeing this philosophy in action. That philosophy sets the individual clearly in the centre of its 
conceptual world. The child-centredness of the philosophy wells up within the different ways Lindkvist offers the audience the frame. Here each child is positioned, not as generic child objects for medical scrutiny but validated by such language as their 'importance' as 'individuals' supported by the close following term of their 'individuality'. When I read this, it makes me think of the image from the 'Movement and Touch' photograph (Figure C), with the child at the centre of Lindkvist's gaze and of her body's holding. This wording is quickly followed by a mention of drama and movement and these are allied with the visibility of the self and the capacity of children being offered the space, relationship and language to 'be themselves'. Again, this is a term for me that stamps the central position of the child in the work: their expression, sense of selfhood and exploration of their individuality. This is followed by the interesting and ambiguous phrase that children such as Thomas' were just 'being themselves, because, being autistic, they would presumably have no reason to be anything else'. My interpretation of this is that is sees a child, experiencing the phenomena named by adults as 'autism', as an aspect of their individuality: the philosophical starting point sees each child as experiencing in individual, specific ways 'autism' as a part of who they are, rather than as a label that fits them into a set of behaviours they are consigned to. The philosophical position of individuality being encouraged and nurtured through drama and movement then builds from this: - the children are 'themselves'. Rather like the language of 'natural' in the 'Open Sesame' document, here is the notion that drama and movement can enable a 'true' involvement that is different from the cultural form of theatre. This is seen as a special state or process that is different from 'normal circumstances' and this permits the children to be, and to be seen, in different ways. This is positioned in the next paragraph as needing care, skill and training with the danger being that of a child's 'exposure', or the revelation or access is potential harmful. Here the Sesame worker is positioned as someone who works with the client, to enable the child through relationship and the arts processes, to 
be and to be seen as an individual. The Sesame practitioner acts as the child's advocate: 'caring', 'observing' and presenting this perspective to the 'medical team'. I find this attractive, as it positions the traditional medical frame as lacking - and if you accept the argument of the text the absence is a deeply significant one. The Sesame practitioner represents the child's individuality and identity and adds to the other professionals' knowledge. Before seeing the individual, Thomas, over time, then Lindkvist's frame says much to me about the ways in which philosophy and practice connect to centre the individual child, Thomas, at the centre of the work and invites a 'different vision' from the medicalised norm.

\section{Conclusion}

Like any act of intuition, this engagement with the Sesame Archive and Billy Lindkvist has held a variety of feelings and responses. The randomness felt exciting: it helped me enter into the different items and enabled me to think and reflect upon elements of Lindkvist's work. The material connected me with her experiences in London, Africa, New Orleans and with moments in hospitals, conference halls, rehearsal rooms and involving research, active work and philosophising. Other things surprise me by their absence, in that none of the fish I landed mentioned directly some of the areas I know are crucial to Lindkvist and to Sesame, such as Jung or the symbolic. I suppose that is the nature of any random selection, though, and of looking at any life - something are seen, some not.

The items have enabled me to gain insight and to reflect on a diverse set of areas of Lindkvist's work. They have illuminated how drama, movement and creativity and the ways she worked with others through film, pamphlet, lecture and demonstration to share her insights and inspire others are powerful themes within her story. My responses have helped 
reveal how interdisciplinarity fuelled her work and its development: how new conceptual spaces were created by her and how these were in a mutual relationship with innovative practices. The Archive has illuminated moments of engagement with people in different settings and of the key contact with others that collaboration held in Lindkvist's work . In my delving into the archive, I feel the privilege of its access and of the vigour, originality, energy and joy that the found materials reveal of Lindkvist's life and of those who came into contact with her. 


\section{References}

Adams, T. E., Holman Jones, S., \& Ellis, C. 2015. Autoethnography: Understanding Qualitative Research. New York: Oxford University Press.

Anonymous. 2010. A Thousand and One Nights. Translated by Dawood, N. London: Penguin ,Angrosino, M.V. 2005. Projects in Ethnographic Research. New York: Waveland Press

Hougham, R. and Jones, B. 2017. Dramatherapy: Reflections and Praxis. London: Palgrave Jung, C. 1954. The Psychology of the Transference, Collected Works: Volume 16. London: Routledge

Keplye, D.R. 1984. "Sampling in Archives: A review", American Archivist. 47 (3): 237-242 Maréchal, G. 2010. “Autoethnography”. In A. J. Mills, G. Durepos \& E. Wiebe. Eds., Encyclopedia of case study research. Thousand Oaks, CA: Sage Publications

Newton, S.M. 1974. Health, Art and Reason: Dress reformers of the Nineteenth century. London: John Murray .

Pearson, J., Smail, M. and Watts, P. 2013. Dramatherapy With Myth and Fairytale: The Golden Stories of Sesame. London: Jessica Kingsley Publishers

Wethered, A. 1973. Drama and Movement in Therapy. London: Macdonald \& Evans White, R. 2001. Obituary Stella Mary Newton. The Guardian. Accessed January 172018. https://www.theguardian.com/news/2001/may/26/guardianobituaries

The film referred to in this article can be located, along with other Sesame Films, at: BFI Education Films for Sesame http://www.bfi.org.uk/films-tv-people/4ce2b94a7f91b 